\title{
Research on Teaching Objectives Adjustment of Interpreting Course at University of Applied Sciences under Competence-Based Language Teaching (CBLT)
}

\author{
Chen Liu* \\ Dept. of Foreign Language Studies \\ Xiamen University Tan Kah Kee College \\ Zhangzhou, China
}

\author{
Ning Jin \\ Dept. of English \\ Dalian Neusoft University of Information \\ Dalian, China
}

\begin{abstract}
This thesis focused on the teaching objectives of interpreting course at university of applied sciences, discussed with qualitative and quantitative research methods, finally determined the adjustment scheme based on the competencebased language teaching (CBLT). It was found that 1) The existing interpreting syllabus may not be setting the realistic weight-loss objectives for students at the university of applied sciences so that many failed to meet with limited time of a semester; 2) The lack of requirements for application skills caused excessive concern about the knowledge input instead of the output when dealing with the interpreting practice; 3) Interest development should be added due to its significance in interpreting learning.
\end{abstract}

Keywords-interpreting teaching; teaching objectives; universities of applied sciences; competence-based language teaching (CBLT)

\section{INTRODUCTION}

The concept of the university of applied sciences has been pointed out in 2017 by the State Council of the People's Republic of China. As early as 2004, when 48 universities of applied sciences were established in China, research related to the cultivation on application-oriented talents have already begun [4]. In 2013, the establishment of the Association of Universities (Colleges) of Applied Sciences marked the commencement of the substantial development of universities of applied sciences in China. The mission for the association is to formulate the construction planning for university of applied sciences, promote education reform and innovation, and serve the national and regional economic and social development.

\section{A. Interpreting Teaching at Universities of Applied Sciences}

The research on interpreting teaching in China has achieved considerable accomplishments for the past decade and has been promoting the in-depth development of teaching practice. However, since most members within the association have transformed from vocational school to university of applied sciences, few scholars in China shifted to delve into the study on interpreting teaching at university of applied sciences correspondingly. Limited research from major scholars can be summarized into the following major categories: interpreting teaching reform, mode of interpreting talent cultivation, interpreting curriculum development, interpreting practice teaching and project-based interpreting teaching.

Zhang Manni [6] discussed the similarities and differences between business English majors and English majors in interpreting teaching after the official release of the English Teaching Guideline for English Majors in Colleges and Universities, proposed that college English teachers should constantly update teaching concepts under the national education policies and new measures in professional construction.

Zheng Ying [7] carried out a teaching reform in teaching procedure, contents of practice training and formative evaluation combined with the orientation and goal of undergraduate interpreting teaching under the status of English majors at universities of applied sciences, explored the distinctive teaching methods in accordance with the law of cognitive development of local university students. Huang Zhenzhen [3] put forward that the courses of business English interpreting should be brought into the training system of English majors based on the practice of enterprise training, and the appropriate teaching materials should be compiled and tested in a more reasonable way in accordance with the traits of universities of applied sciences, so that the courses can truly serve the needs of the students and conform to the trend and requirements of the reform.

Zou Yingli [8] discussed the reform of project-based interpreting teaching at universities of applied sciences from the aspects of teaching content, teaching methods and the effectiveness of teachers' guidance, proposed that the status of business English majors at universities of applied sciences under the project-based teaching mode is not optimistic. It is justified that teachers should change the traditional teaching methods, develop the business English interpreting communication platform and focus more on the cultivation of students' practical ability in business English interpreting, so as to give full play to the advantages of the project-based teaching mode and make students realize the importance of interpreting and actively participate in English learning. 
English Teaching Guideline for English Majors in Colleges and Universities (Revised in 2015) defines interpreting teaching as "translation teaching" in terms of teaching objectives [5]. However, students with less solid language skills at universities of applied sciences prove to be incapable on their interpreting study in accordance with the objectives of "translation teaching", consequently, teachers would face great difficulty in designing the curriculums of interpreting. In addition, universities of applied sciences are confronted with a great challenge on the transformation of talent training mode, traditional ways of interpreting teaching cannot satisfy the market needs of the English talents, the demand of interpreting courses reform proves to be particularly urgent.

\section{B. Teaching Objectives Under Competence-Based Language Teaching (CBLT)}

It would be better to be taken into a broader field of curriculum development first and foremost when delving into the subject. The field of curriculum development was first systematized by Tyler in 1949, who articulated four fundamental questions that must be answered by any curriculum developer:

1) What educational purposes should a school seek to attain?

2) What educational experiences can be provided that are likely to attain those purposes?

3) How can educational experiences be effectively organized?

4) How can we determine whether these purposes have been attained?

In the context of language teaching, the first two questions have to do with the syllabus design [2]. Syllabus design is the selection, sequencing, and justification of the content of the curriculum. In language teaching, content selection will include selecting linguistic features as well as experiential content. The selection process is guided by needs analyses of various kinds, which provides the designer with a basis both for content specification and for the setting of goals and objectives [2]

The competency-based approach has had a major influence on syllabuses in particular sectors of the educational systems in most English-speaking countries, including Australia, New Zealand, the United Kingdom and the United States. Competence-based language teaching (CBLT) first emerged in the United States in the 1970s and refers to an educational movement focused on outcomes or outputs of learning in the development of language programs, advocates defining educational goals in terms of precise measurable descriptions of the knowledge, skills, and behaviors students should possess at the end of a course of study, and was widely adopted in vocationally oriented education and in adults' ESL programs. By the end of the 1980s, CBLT had come to be accepted as the "state-of-the-art" approach to ESL by national policymakers and leaders in curriculum development [1]. The most recent realization of a CBLT perspective in the US is found in the "standards" movement, which has dominated educational discussions since the 1990s.

Competencies differ from other goals and objectives in that they describe the students' ability to apply basic and other skills in situations that are commonly encountered in everyday life. CBLT seeks to develop students' competencies from what they know about language to what they do with it, especially essential skills, knowledge, attitudes, and behaviors required for the effective performance of a real-world task or activity. The final goal is to enable students to become autonomous individuals capable of coping with the demands of the world.

\section{RESEARCH DESIGN}

Needs analysis, in particular, provide a basis for designers when determining the teaching objectives in terms of the previous study of syllabus design. In this case, interviews would be given to the relative groups with quantitative research on final test scores of students for data collection and analysis. Steps for conducting the needs analysis are listed below.

1) Interview full-time interpreting teachers to check their attainment of the teaching objectives;

2) Analyze students' formative and summative assessment performance of interpreting to evaluate their attainment of the teaching objectives;

3) Determine the teaching objectives of interpreting course at universities of applied sciences.

\section{RESUlTS AND DISCUSSION}

The general teaching objectives for interpreting course at university of applied sciences aims at cultivating interdisciplinary and applied talents with a broad range of knowledge in social affairs and social activities, and mastering cross-cultural communication skills and common techniques of interpreting in the three stages of comprehension, retention, and expression through audio-visual practice, shorthand, and interpreting simulation exercises so as to meet the needs of interpreting work in the future.

Specifically, the teaching objectives for interpreting course are as follows:

1) Understand the interpreting background knowledge (definition, characteristics, classification, and interpreting resources and certification) and basic theory of interpreting

2) Master practical skills (source language listening, fiures translation, scene sentence/vocabulary, interpreting notes, primary translation strategies and methods, topical instant language organization), etc.

3) Apply the interpreting skills in a variety of social activities, and the practical ability to cope with the dilemma of interpreting in real scenes.

The research conducted the interview and analyzed the performance of formative and summative assessment for determining the teaching objectives of interpreting course at universities of applied sciences.

\section{A. Interview with Interpreting Teachers at the University of Applied Sciences}

Interpreting teachers are required not only to be professional in English as general English teachers, but an English proficiency in comprehension and application with a higher level of English listening, speaking, reading, writing and 
translating skills. Specifically, teachers should possess solid professional knowledge with high proficiency in bilingual translation skills and practical interpreting experience.

In terms of the research design, three qualified interpreting teachers at a certain university of applied sciences were interviewed after their finishing of the teaching contents of a semester. The interviewees make comments of their teaching objectives attainment in three aspects are as follows:

1) Knowledge Objectives Attainment

Teacher A: most of the students are capable of finishing a simple sentence interpreting, but fail to conduct a paragraph interpreting due to the lack of retention and retelling practice. Besides, note-taking exercise is insufficient, and consequently, their capabilities of short term memory are not cultivated adequately, but it is pleased to see that a majority of students get a brief understanding of the basic theory of interpreting, and show a great interest in further learning in the future.

Teacher B: students can basically understand the interpreting background knowledge but show less concern about the cross-cultural awareness cultivation throughout the interpreting learning. Moreover, their level of proficiency in English should be enhanced.

Teacher C: it is expected to see an improvement in transforming the Chinese sentence structure into English when dealing with the $C-E$ interpreting practice, but it comes with great difficulty for students to deliver the meaning of certain sentences with appropriate, accurate and precise words.

2) Ability Objectives Attainment

Teacher A: some of the students enable to use accurate language and non-verbal communication skills (gesture, eye contact, gestures, etc.) when dealing with an interpreting practice, but most of them find it hard to identify the scenarios of interpreting and use appropriate language expressions within varies social activities and different contexts of cross-cultural communication.

Teacher B: we got depressed in failing to cultivate students' problem analysis ability, especially when faced with the semantic gap in their interpreting practice.

Teacher C: it makes possible for students to master some technical terms when learning in class and after class, but they fail to apply those technical terms to the practice of interpreting, and some of their interpretings turn out to be a little bit rigid, and the patterns of the sentence structure tends to be poor in flexibility.

3) Quality Objectives Attainment

Teacher A: two of the students in class ask more learning materials for further study after class, while the rest of them show less interest in learning to interpret on their own.

Teacher B: most of the students show less confidence in learning interpreting, and they find it hard to attain the learning objectives throughout the course and claim that they will never do such thing anymore when they graduate from school.

Teacher C: one of the students joined a national interpreting contest and got the second prize, he shows great interest in learning interpreting and high demand in developing his overall English proficiency in his school days, some of the students were encouraged and became interested in interpreting gradually.

B. Results and Analysis of the Performance in Formative and Summative Assessment

The evaluation of students' learning outcomes consists of two parts: formative assessment and summative assessment.

The formative assessment accounts for $50 \%$ of the total, mainly by their classroom performance (10 points), interpreting project (20 points), homework (10 points), vocabulary test (10 points) and attendance.

The average score of the formative assessment is 33 points and the passing rate is $89 \%$, which reflects that most of the students' learning attitudes are basically favorable, and they can complete various assessment tasks and meet the standard requirements. The performance of Class 200412-002 is poorer (only 4.4 points) due to their insufficient preparation of homework, and the tasks assigned are not completed in time, compared with class 200412-005 and class 200412-006, with an average score of 7.3 points or more. In addition, certain students have more deductions of absence from school, which affects the average score of the class.

The summative assessment of this course was designed in the form of Chinese-English impromptu interpreting. Students were required to interpret Chinese into English at a given time. The final exam was adhered to the principle of "separation of teaching and test" with a total of 12 different test papers, students were required to finish the test in between $6-8$ minutes. The language ability indicators, key points and difficult points, score ratio for each indicator and summative assessment requirements are as follows.

TABLE I. CRITERIA OF SUMmative ASSESSMENT

\begin{tabular}{|c|c|c|c|c|}
\hline Language Ability Indicators & $\begin{array}{c}\text { Key } \\
\text { Point }\end{array}$ & $\begin{array}{c}\text { Difficult } \\
\text { Point }\end{array}$ & Ratio & Assessment Requirement \\
\hline Pragmatic knowledge & Yes & Yes & $20 \%$ & Master English pragmatic rules \\
\cline { 3 - 4 } Country-Specific Culture Knowledge & No & Yes & $5 \%$ & $\begin{array}{c}\text { Reflect the consciousness of country-specific culture and corresponding coping } \\
\text { strategies }\end{array}$ \\
\hline Language Using & Yes & No & $25 \%$ & Apply English language skills and short-term memory skills \\
\hline
\end{tabular}




\begin{tabular}{|c|c|c|c|c|}
\hline \multicolumn{4}{|c|}{ Cont. to TABLE I. } \\
\hline $\begin{array}{c}\text { Introducing, Absorbing and Re- } \\
\text { Creating }\end{array}$ & Yes & Yes & $15 \%$ & Use words, phrases and sentence patterns flexibly and innovatively \\
\hline Construction of Content & Yes & No & $15 \%$ & $\begin{array}{c}\text { Identify different scenarios of interpreting, and use appropriate language } \\
\text { expressions }\end{array}$ \\
\hline $\begin{array}{c}\text { Verbal and Interpersonal } \\
\text { Communication }\end{array}$ & Yes & Yes & $15 \%$ & Use concise, clear and precise language \\
\hline Learning Attitudes and Habits & No & No & $5 \%$ & Understand the background information on interpreting and be prepared \\
\hline
\end{tabular}

The pass rate of the summative assessment is $92 \%$, with an average score of 73 points, $60 \%$ of the students are above 70 points, of which 80 points or more of the students account for $29 \%$, indicating that most students have a good attitude and an adequate preparation for the test. However, there are still some students fail to meet the standard of qualified interpreting. The proposition of the summative assessment follows the requirements of the syllabus with a moderate level of difficulty. Most students have sufficient preparation, consequently, there is not an obvious distinction on their performance for the final test (see TABLE II).

TABLE II. Summative AsSESSMENT Results

\begin{tabular}{|c|c|c|c|c|c|c|c|}
\hline Teaching Class & Average Score & Pass Rate & Failure Rate & $60-69$ & $70-79$ & $80-89$ & $90-100$ \\
\hline $200412-001$ & 74.6 & $100.0 \%$ & $0.0 \%$ & $36.1 \%$ & $27.8 \%$ & $25.0 \%$ & $11.1 \%$ \\
\hline $200412-002$ & 71.1 & $92.0 \%$ & $8.0 \%$ & $32.0 \%$ & $44.0 \%$ & $12.0 \%$ & $4.0 \%$ \\
\hline $200412-003$ & 74.8 & $95.8 \%$ & $4.2 \%$ & $33.3 \%$ & $29.2 \%$ & $16.7 \%$ & $16.7 \%$ \\
\hline $200412-004$ & 74.3 & $87.5 \%$ & $12.5 \%$ & $25.0 \%$ & $33.3 \%$ & $20.8 \%$ & $8.3 \%$ \\
\hline $200412-005$ & 71.2 & $83.9 \%$ & $16.1 \%$ & $29.0 \%$ & $25.8 \%$ & $22.6 \%$ & $6.5 \%$ \\
\hline $200412-006$ & 77.3 & $100.0 \%$ & $0.0 \%$ & $0.0 \%$ & $75.0 \%$ & $25.0 \%$ & $0.0 \%$ \\
\hline Total & 73.3 & $92.4 \%$ & $7.6 \%$ & $30.6 \%$ & $32.6 \%$ & $20.1 \%$ & $9.0 \%$ \\
\hline
\end{tabular}

\section{Discussion}

In terms of the interview and the grade analysis report, the problems of the existing teaching objectives were summarized and corresponding solutions were provided which are listed below:

1) The existing interpreting syllabus may not be setting the realistic weight-loss objectives for students at the university of applied sciences so that many failed to meet with limited time of a semester. Most students at university of applied sciences are at a low level of English proficiency even if they finish basic courses in the first two years;

2) Retention and retelling skills training, the basis of interpreting learning, should be introduced to interpreting teaching objectives;

3) CBLT emphasizes on the outcomes of learning, or, what to do with language instead of what they know about it, that is to say, CBLT focuses on using language to deal with certain tasks. The lack of requirements for application skills, especially for the analysis of the problem and solving caused excessive concern about the knowledge input instead of the output when dealing with the interpreting practice;

4) Learning with interest shows highly relevant to their achievements based on the previous research, and it should be added and clearly stated in the teaching objectives. Students at university of applied sciences need to be cultivated with interesting interpreting materials and different in-class activities, and it would be not only better for developing their interest in learning interpreting, but beneficial for their further learning of this subject.

The teaching objectives for interpreting course at university of applied sciences are determined when considering the problems and suggestions provided by the new findings above, specific teaching practice and the expected learning effect, see TABLE III.

TABLE III. TEACHING OBJECTIVES OF INTERPRETING COURSE

\begin{tabular}{|c|c|c|}
\hline $\begin{array}{c}\text { Teaching Objectives } \\
\text { Classification }\end{array}$ & Language Ability Indicators & Expected Learning Effect \\
\hline \multirow{3}{*}{ Knowledge Objectives } & Pragmatic knowledge & Master English pragmatic rules \\
\cline { 2 - 3 } & Country-Specific Culture & Understand the basic theory of interpreting \\
\cline { 2 - 3 } & Knowledge & Cultivate an international vision and cross-cultural awareness \\
\cline { 2 - 3 } Ability Objectives & Problem Analysis & Understand the country-specific culture of English-speaking countries \\
\cline { 2 - 3 } & Language Using & Interpret the semantic gap with appropriate sentence patterns and phrases \\
\cline { 2 - 3 } & Construction of Content & Master relevant technical terms in a certain field \\
\cline { 2 - 3 } & Apply technical terms and English language skills to the practice of interpreting \\
\cline { 2 - 3 } & Verbal and Interpersonal \\
& Communication & Understand the role of interpreters in social activities and cross-cultural communication \\
\cline { 2 - 3 } & Identify different scenarios of interpreting, and use appropriate language expressions \\
\cline { 2 - 3 } & Use concise, clear and precise language in interpreting activities. \\
\cline { 2 - 2 } & $\begin{array}{c}\text { Use appropriate language, style and non-verbal communication (gesture, eye contact, } \\
\text { gestures, etc.) throughout the interpreting process }\end{array}$ \\
\hline
\end{tabular}




\begin{tabular}{|c|c|c|}
\hline \multicolumn{2}{|c|}{ Cont. to TABLE III. } \\
\hline \multirow{2}{*}{ Quality Objectives } & Learning Attitudes and Habits & Conduct systematic and regular professional training \\
& & Able to develop an interest in learning interpreting \\
\hline
\end{tabular}

Some of the objectives are retained and specified, for instance, the pragmatic and country-specific culture knowledge, and students are expected to understand the basic theory of interpreting and country-specific culture of English-speaking countries. As for ability objectives, technical terms, retention and retelling skills are emphasis, students are required to master and apply those skills into the interpreting practice, furthermore, considering the learning condition at university of applied sciences, the requirements for students are lowered on their flexibility and re-creating of interpreting, compared with the higher standards on identifying and coping with different interpreting scenarios. In addition, interest development is added to the quality objectives.

\section{CONCLUSION}

Teaching reform should be started with the teaching objectives, especially for universities of applied sciences. The study adopted competence-based language teaching (CBLT) to deal with the adjustment of the objectives of interpreting course at university of applied sciences, major findings are as follows:

1) The existing interpreting syllabus may not be setting the realistic weight-loss objectives for students at the university of applied sciences so that many failed to meet with limited time of a semester;

2) Retention and retelling skills training should be introduced to interpreting teaching objectives;

3) The lack of requirements for application skills caused excessive concern about the knowledge input instead of the output;

4) Interest development should be added to the interpreting teaching objectives.
In addition, it is highly recommended that the determination of teaching objectives should consider the needs provided by students and consistent with the teachers' teaching practice, as for students from universities of applied sciences, language proficiency training and interest development should be focused as primary targets for interpreting teaching.

\section{REFERENCES}

[1] Auerbach, E. Competency-based ESL: One Step Forward or Two Steps Back? [J]. TESOL Quarterly 1986(3): 411-429.

[2] Nunan, David. Syllabus Design [A]. Celce-Murica, Marianne, ed. Teaching English as a Second or Foreign Language [C]. Beijing: Foreign Language Teaching and Research Press, 2006: 55-56.

[3] Huang Zhenzhen. Curriculum Development of Business English Interpreting at Universities of Applied Sciences: Based on the Practice Survey of Enterprise Training [J]. Overseas English, 2016: 66-68. K. Elissa, "Title of paper if known," unpublished. (In Chinese)

[4] Liu Yourong. A Study on the Development of Upgraded Application Oriented Undergraduate Colleges [D]. Nanjing University, 2011:25. (In Chinese)

[5] Wang Nina. The Orientation of Interpreting Teaching of English Majors and Some Teaching Problems [J]. Journal of Inner Mongolia University for Nationalities, 2009(1):161-162. (In Chinese)

[6] Zhang Manni. On Business English Majors and Interpreting Teaching at Universities of Applied Sciences under the English Teaching Guideline for English Majors in Colleges and Universities [J]. Course Education Research, 2018(38):108-109. (In Chinese)

[7] Zheng Ying, Ke Yingen, Wang Shanshan. Exploration of the Teaching Reform of Undergraduate Interpreting Course for English Majors at Local Universities of Applied Sciences [J]. Journal of Chaohu College, 2018(4):127-130. (In Chinese)

[8] Zou Yingli. Practice and Exploration of Project-based Teaching of Business English Courses at Universities of Applied Sciences: Taking the Course of Business Interpreting as an Example [J]. Discussion and Practice of Education and Teaching Methods, 2016(7):245-246. (In Chinese) 